Check for updates

Cite this: RSC Adv., 2019, 9, 34547

Received 19th August 2019

Accepted 16th October 2019

rsc.li/rsc-advances
DOI: $10.1039 / c 9 r a 06480 j$

\section{The photoluminescence, field emission and femtosecond nonlinear absorption properties of Al-doped ZnO nanowires, nanobelts, and nanoplane-cone morphologies}

\begin{abstract}
Yu-Tong Cao, Yu Cai, Cheng-Bao Yao, D * Sheng-Bin Bao and Yue Han
Al-doped $\mathrm{ZnO}(\mathrm{AZO})$ nanowires, nanobelts and nanoplane-cone nanostructures have been successfully synthesized. The structural, photoluminescence (PL) and field emission (FE) properties of AZO nanowires have been characterized. The dependence of the PL properties of AZO nanostructures versus excitation laser power in the range from 1 to $12 \mathrm{~mW}$ and temperature in the range of 10-273 K was discussed. The $\mathrm{PL}$ measurement results demonstrated that the ultraviolet emission came from a near band edge emission, and two peaks in visible light region were due to deep-level emission. Moreover, the AZO nanowires have a relatively stronger ultraviolet emission than other kinds of samples. The FE measurements indicate that the turn-on field for the nanoplane-cone structure is $2.52 \mathrm{~V} \mu \mathrm{m}^{-1}$, which is smaller than $4.42 \mathrm{~V} \mu \mathrm{m}^{-1}$ for nanowires and $5.28 \mathrm{~V} \mathrm{\mu m}^{-1}$ for nanobelts. In addition, the nonlinear absorption properties of AZO nanowires were measured using a femtosecond Z-scan technique. The effect of morphology on the nonlinear optical absorption properties of AZO nanowires was studied. From the results, the AZO nanowires show reverse saturable absorption (RSA) behavior. Furthermore, the results show that the order of magnitude of the nonlinear absorption coefficient for $A Z O$ nanowires is $\sim 10^{-2} \mathrm{~cm}^{3} \mathrm{GW}^{-2}$. Our results show that AZO films are a promising candidate in further optoelectronic device applications.
\end{abstract}

\section{Introduction}

1D pure zinc oxide (ZnO) and metal-doped $\mathrm{ZnO}$ nanostructures are considered to have potential applications in electronics, and photon and sensor components due to their excellent optical and electrical properties. ${ }^{1-8}$ Also the metal doping amount controls the optical band gap of ZnO. Particularly, in earlier reports, ${ }^{9,10} \mathrm{Ga}, \mathrm{Al}$ and In metal doped $\mathrm{ZnO}$ materials have received considerable attention due to their interesting photoelectric and nonlinear optical properties. $\mathrm{Al}$ is an excellent dopant for $\mathrm{ZnO}$ due to it having a single positive $\mathrm{Al}^{3+}$, and the $\mathrm{Al}^{3+}$ has a smaller ionic radius than $\mathrm{Zn}^{2+} \cdot{ }^{11} \mathrm{Al}$ is preferable as a dopant source; it is more suitable to occupy the interstitial site. In addition, due to the doping of aluminum, the resistivity of the zinc oxide nanostructure, the high transmittance in the visible light region and the thermal stability are improved. To date, some researchers have studied a variety of $\mathrm{Al}$ doped $\mathrm{ZnO}$ (AZO) nanostructures, among which thin films, ${ }^{12-14}$ nanofibers, ${ }^{15}$ micron rods, ${ }^{16}$ nanowires, ${ }^{17,18}$ nanorods ${ }^{19}$ and nanoparticles $^{20,21}$ have been successfully prepared by various

Key Laboratory of Photonic and Electric Bandgap Materials, Ministry of Education, School of Physics and Electronic Engineering, Harbin Normal University, Harbin, 150025, Heilongjiang Province, China. E-mail: yaochengbao5@163.com methods. For AZO thin films, F. Khan et al. ${ }^{12}$ have reported influence of excitation wavelength on PL spectra of AZO films. M. Chen et al. ${ }^{13}$ have reported surface characterization of transparent conductive oxide AZO films. M. Shirazi et al. ${ }^{14}$ have reported PL of AZO film by spray pyrolysis method. The results show that the near band edge (NBE) emission in PL spectra shifts to shorter wavelengths and Fermi surface shifts to conduction band with increasing the $\mathrm{Al}$ content. Y. Liu et al. ${ }^{15}$ found a decrease in green emission intensity of AZO nanofibers with increasing the $\mathrm{Al}$ concentration. Compared with other dopants ZnO nanomaterials, AZO nanostructures have been presented for the high conductance duo to provided more electrons, which can be expected to have a green emission band, a low turn-on electric field (EF) and a high emission current (EC).$^{20} \mathrm{~J}$. L. Wang et al. ${ }^{21}$ have reported FE characteristics of AZO nanowires at different oxygen annealing temperature. AZO film has been reported by many researchers. Hence, it is important to investigate the influence of the dopants on the structural, morphologies and properties of $\mathrm{ZnO}$ nanostructure..$^{22,23}$ However, the morphologies of 1D AZO nanomaterial are seldom reported. The influence of morphology on the structural, photoelectric and ultrafast nonlinear optical behavior properties of AZO nanomaterials is still lacking. 
Table 1 Experimental conditions maintained for the growth of AZO nanostructure

\begin{tabular}{llllll}
\hline Sample & $\begin{array}{l}\text { Quality ratio } \\
\text { of ZnO : Al }\end{array}$ & $\begin{array}{l}V \\
(\mathrm{sccm})\end{array}$ & $T\left({ }^{\circ} \mathrm{C}\right)$ & $\begin{array}{l}t \\
(\mathrm{~min})\end{array}$ & $L(\mathrm{~cm})$ \\
\hline Nanowires & $5: 1$ & 20 & 1250 & 30 & 21.4 \\
Nanobelts & $4: 1$ & 60 & 1250 & 30 & 16.2 \\
Nanoplane-cone & $4: 1$ & 100 & 1250 & 30 & 17.0 \\
\hline
\end{tabular}

In this work, AZO nanostructures with nanowires, nanobelts and nanoplane-cone morphologies had been successfully synthesized. We study the effect of different parameters on the morphologies and nanostructures. The results show that different experimental parameters lead to different sample morphologies. The room and low temperature photoluminescence (RTPL/LTPL) spectra and FE properties of the AZO nanostructures were further investigated. The results show that different morphologies and components affect the location and intensity of the emission peak. The resulting FE showed that the superior $\mathrm{FE}$ properties are attributed to the better morphologies. Ultrafast nonlinear optical studies in semiconductor materials have proven extremely powerful in understanding photoelectric properties of materials that are crucially important in optical devices applications.

\section{Experiment}

The powder mixture of $\mathrm{ZnO}$ and $\mathrm{Al}$ as evaporation source was placed into a ceramic boat and loaded into the tubular furnace. And the Si (100) substrates with Au films were placed downstream from the powders. Detailed experimental conditions (the preset temperature $\left(T /{ }^{\circ} \mathrm{C}\right)$, quality ratio of $\mathrm{ZnO}: \mathrm{Al}$, flow rate of carrier gas $(\mathrm{V} / \mathrm{sccm})$, the evaporation time $(t / \mathrm{min})$, distance between substrate and evaporation source $(L / \mathrm{cm}))$ are listed in Table 1. Two important factors are responsible for the growth of AZO nanostructures: the formation of crystalline nuclei and axial growth of AZO nuclei. The formation of nuclei depends on experimental conditions parameters. When the temperature exceeds $1250{ }^{\circ} \mathrm{C}$, $\mathrm{ZnO}$ is easily separated into $\mathrm{Zn}^{2+}$ and $\mathrm{O}^{2-}$, and $\mathrm{Al}$ is easily separated into $\mathrm{Al}^{3+}$. Owing to the fast converge of all ions in low temperature range, nanosized crystal nuclei were generated. In addition, since $\mathrm{ZnO}$ is a polar crystal, where zinc and oxygen atoms are arranged alternatively along the c-axis and the top/bottom surface of $\mathrm{Zn}$ with catalytically active and oxygen with chemically inert terminated, respectively. With the control of gas velocity and distance, various morphologies of AZO nanostructures were formed. Moreover, since $\mathrm{Al}$ atoms have lower vapor pressure than $\mathrm{Zn}$ atoms, the characteristic diameter would be increased with increasing $\mathrm{Al}$ composition. Simply it is directly related to the number of deposited particles. Growth mechanism of 1D-AZO nanostructures was shown in Scheme 1. In the Scheme 1(a), AZO nanowires are up to several tens of microns in length and have a catalyst particle at the tip. In Scheme 1(c), the AZO nanobelts were grown by increasing $\mathrm{ZnO}$ vapor concentration which prompted the growth of nanobelts. However, further increase of doping prompted the growth of nanoplane-cone, due to the difference of radius between $\mathrm{Zn}^{2+}$ ion $(0.074 \mathrm{~nm})$ and $\mathrm{Al}^{3+}$ ion $(0.053 \mathrm{~nm})$, which changes the interplanar crystal spacing, and results in a measurable lower angle shift of the (100) and (101) peaks, as shown in Scheme 1(d). But $\mathrm{Al}$ can be incorporated in $\mathrm{ZnO}$ system either as a substituent for $\mathrm{Zn}^{2+}$ and suppress the growth of ZnO. X-ray diffraction (XRD), field emission scanning electron microscope (SEM), energy dispersive spectroscopy (EDS), transmission electron microscopy (TEM), high resolution transmission electron microscopy (HRTEM), selected area electron diffraction (SAED), field emission auger electron spectrometers (FEAES), RTPL and LTPL characterization for samples were performed, respectively. The Z-scan experiments are performed using a Q-switched, frequency doubled Ti:sapphire laser producing $150 \mathrm{fs}$ laser pulses with a pulse repetition rate of $1 \mathrm{kHz}$ at wavelength of $800 \mathrm{~nm}$. Basically, in this technique the nonlinear sample is scanned through the focal plane of a tightly focused Gaussian beam. Unstability of the Gaussian beam intensity is $\pm 0.2 \%$. These methods are described in detail in previous reports. ${ }^{24}$

\section{Results and discussion}

Fig. 1 shows the XRD pattern of the AZO nanostructures with nanowires, nanobelts and nanoplane-cone morphologies. The diffraction peaks at $2 \theta$ (degrees) of 36.446 are indexed planes of Al. The other diffraction peaks at $2 \theta$ (degrees) are indexed planes of ZnO (JCPDS card no. 76-704). And the lattice constant of AZO nanostructures was smaller than that of the pure $\mathrm{ZnO}(a$

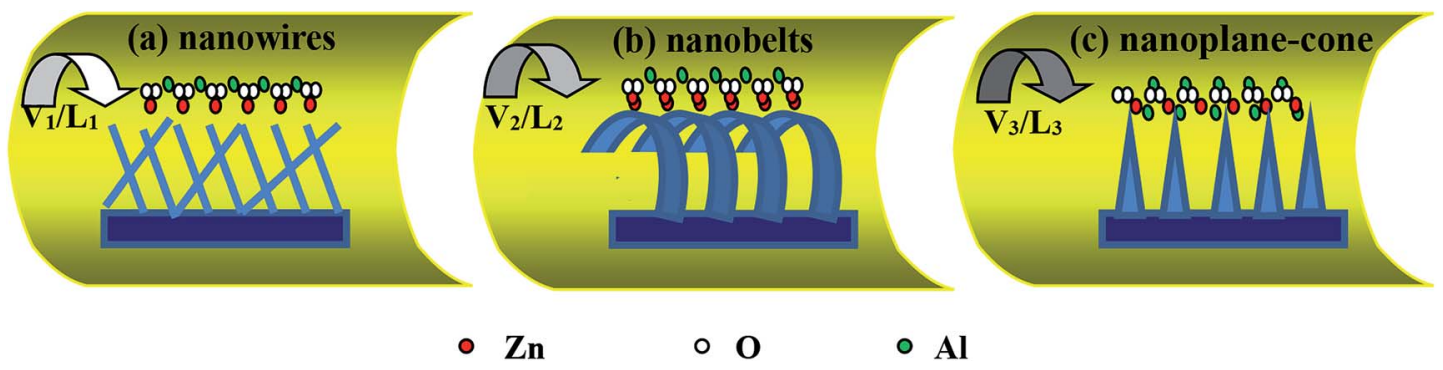

Scheme 1 A schematic illustration of growth mechanism for AZO nanostructures. $V_{1-3}, L_{1-3}$ shows the flow rate of carrier gas and distance between substrate and evaporation source for three samples; (a) nanowires, (b) nanobelts and (c) nanoplane-cones. 


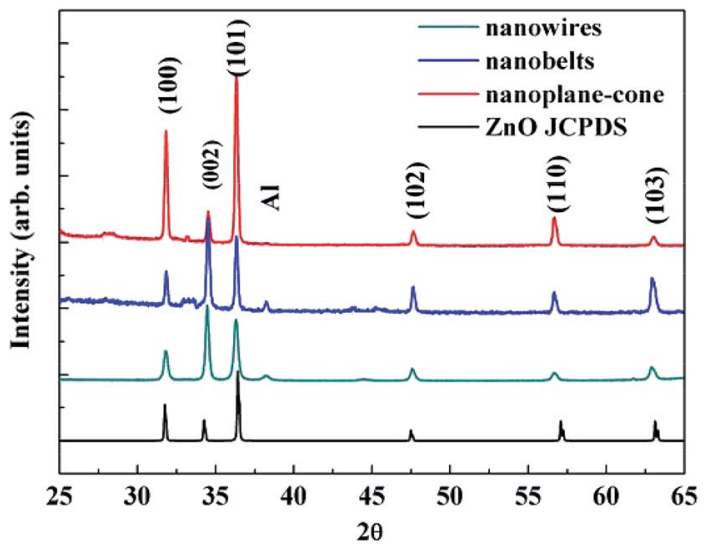

Fig. 1 X-ray diffraction spectrum of AZO nanostructures.

$=0.32475-0.32501 \mathrm{~nm}, c=0.52042-0.52075 \mathrm{~nm}$ (ref. 26)). Since the ionic radius of $\mathrm{Al}^{3+}(0.053 \mathrm{~nm})$ is smaller than the ionic radius of $\mathrm{Zn}^{2+}(0.074 \mathrm{~nm})$, the $\mathrm{Al}$ atom replaces the $\mathrm{Zn}$ atom at the lattice position, resulting in a decrease in lattice constant. In addition, as can be seen from Fig. 1 the (0002) crystalline plane distance decreases, and the diffraction angle increases. So the lattice constant $c$ of AZO nanostructure is smaller than that of the bulk $\mathrm{ZnO}$, all the nanostructures exhibit residual tensile strain.

Fig. 2 (M1, M2 and M3, M = a, b, c) shows a low magnification, high magnification and the cross section thickness of SEM image of all samples. The results showed AZO nanostructures with nanowires, nanobelts and nanoplane-cone morphologies have been successfully synthesized. The insets of Fig. 2 (M3) are magnified SEM image with cross section of such structures. The image shows evidence of the nanostructured morphology of the AZO. It is obvious that the morphology of AZO has quite differences, namely nanowires $(V /$ $d=0.93)$, nanobelts $(V / d=3.7)$, and nanoplane-cone $(V / d=5.9)$. Fig. 2(a) exhibits thickness uniform three-edged 1D nanowires, which has a diameter of around $84 \mathrm{~nm}$ and a total length of several microns (not shown). Fig. 2(b) exhibits hexagonal nanobelts at $312 \mathrm{~nm}$ width and $92 \mathrm{~nm}$ thicknesses. Fig. 2(c) exhibits nanoplane-cone with wide (thick) end and narrow (tip) end. From the results, the diameter of single AZO nanoplanecone is around $600 \mathrm{~nm}$ and $20 \mathrm{~nm}$ (for wide (thick) and narrow (tip) parts of nanoplane-cone), respectively. Fig. 3 shows the typical composition analysis of the AZO nanostructures. EDS demonstrate only $\mathrm{Zn}, \mathrm{O}$ and $\mathrm{Al}$ element. And no peaks are detected from other element materials. In addition, with the
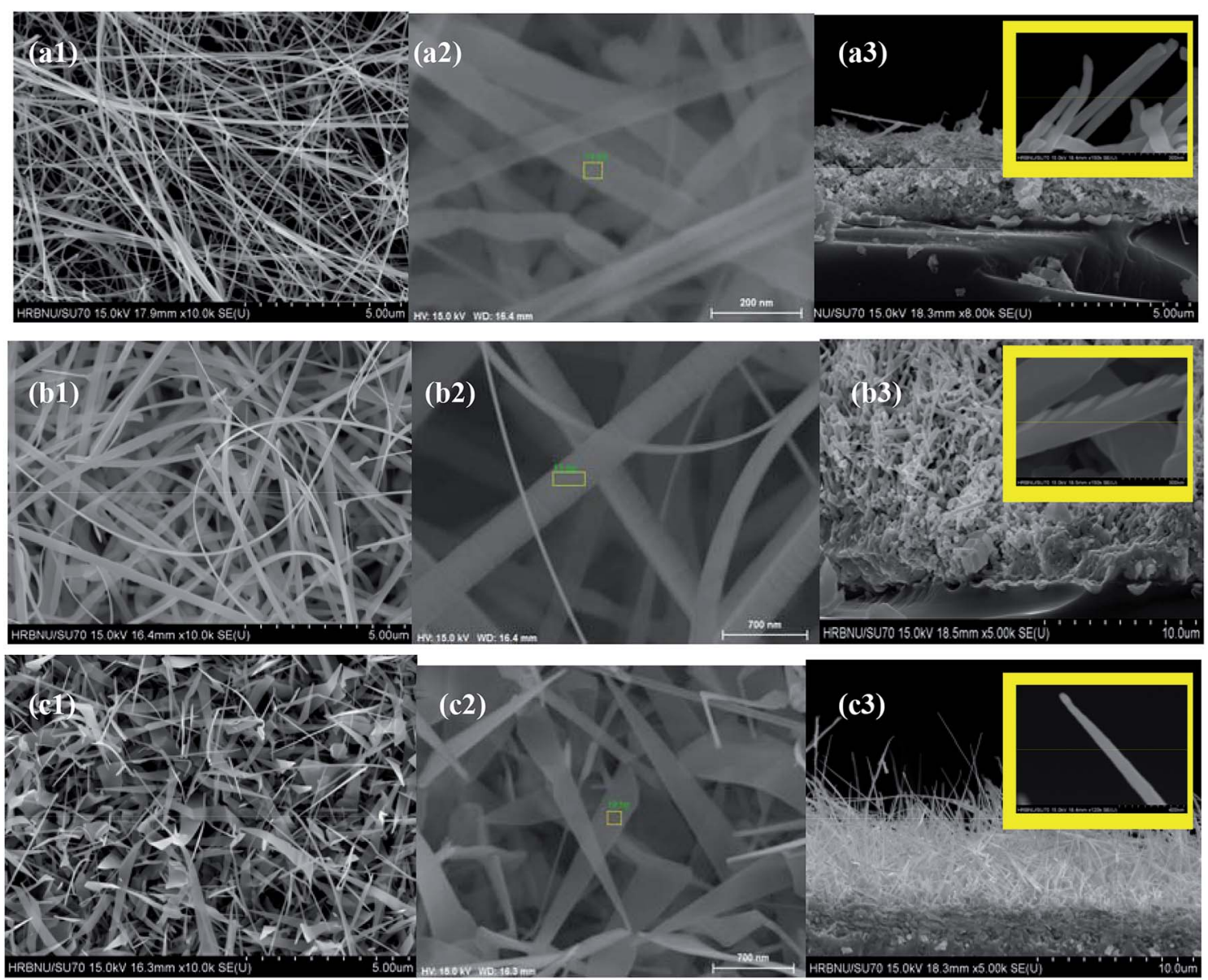

Fig. 2 Schematic SEM diagrams of AZO nanostructures with different morphologies: (a) nanowires, (b) nanobelts, and (c) nanoplane-cone. 
(a)

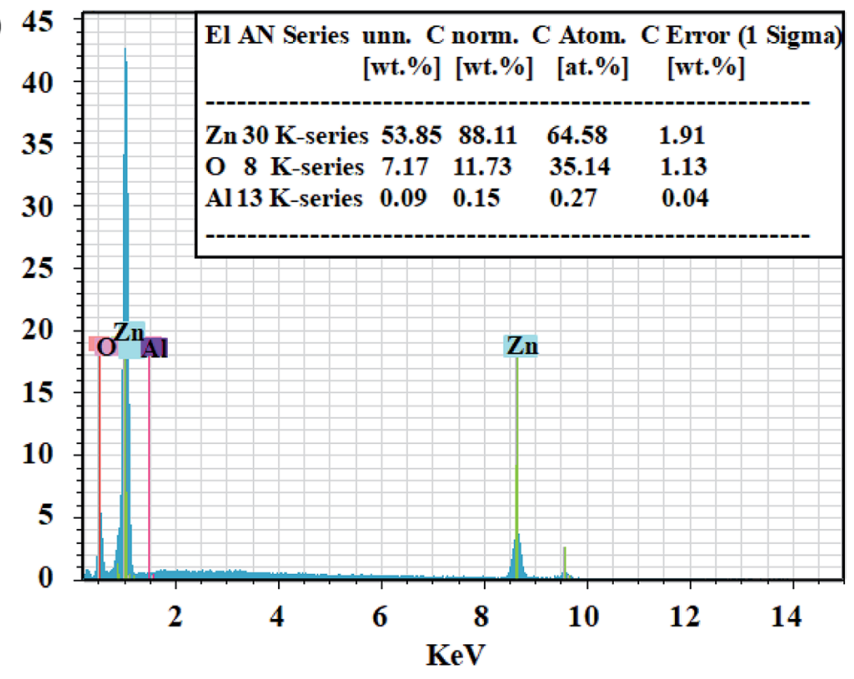

(b)

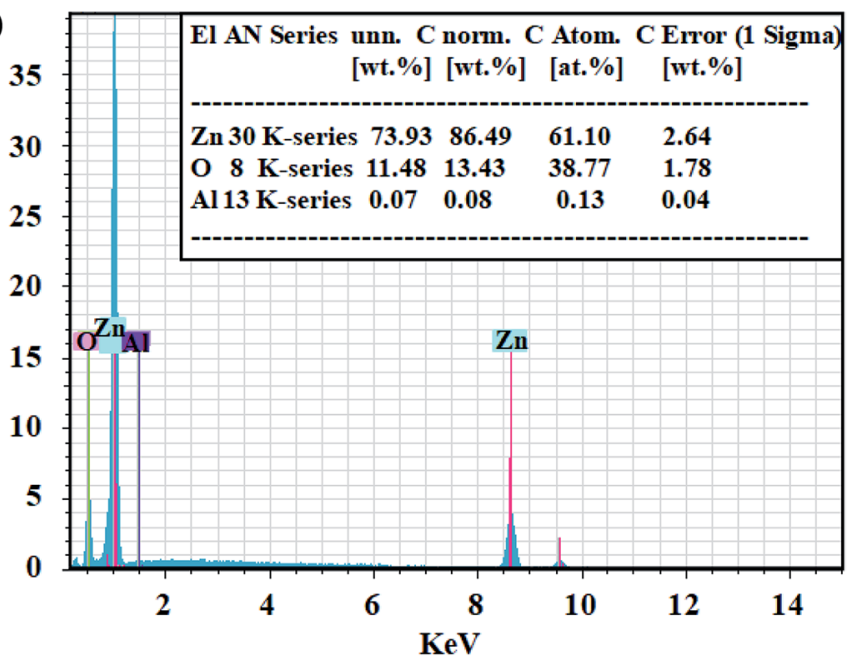

(c)

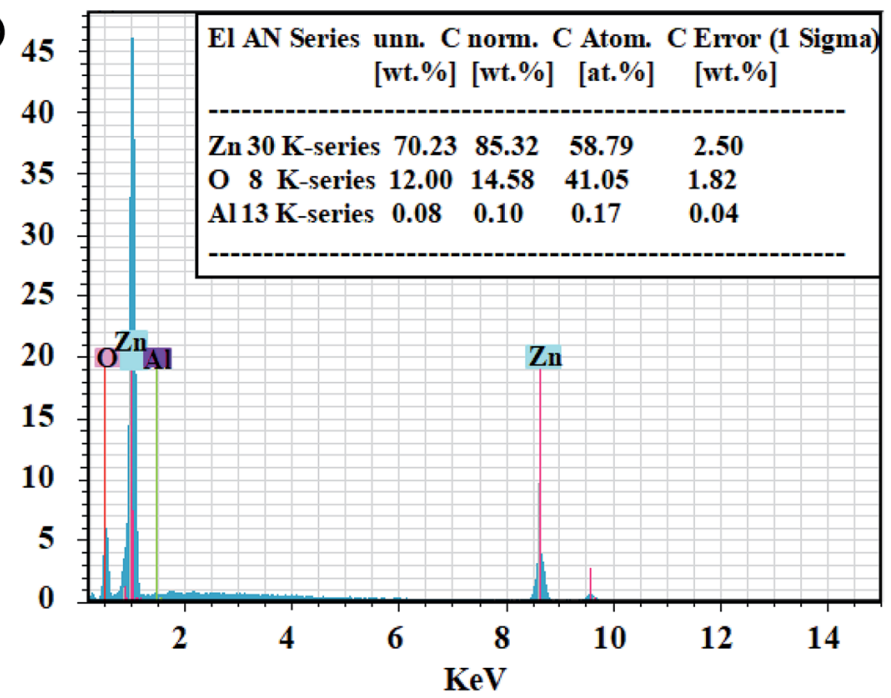

Fig. 3 Schematic EDS diagrams of AZO nanostructures with different morphologies: (a) nanowires, (b) nanobelts, and (c) nanoplane-cone.

increase of distance between substrate and evaporation source, the concentration of incorporated $\mathrm{Al}$ increased (in Fig. 3, at\% of Al for nanowire $>$ nanoplane-cone $>$ nanobelts).
Fig. 4 (M1) shows the TEM characterization of all samples. The Fig. 4 (M2) and (M3) are HRTEM image and SAED pattern, respectively. The diameter of single AZO nanostructures is 

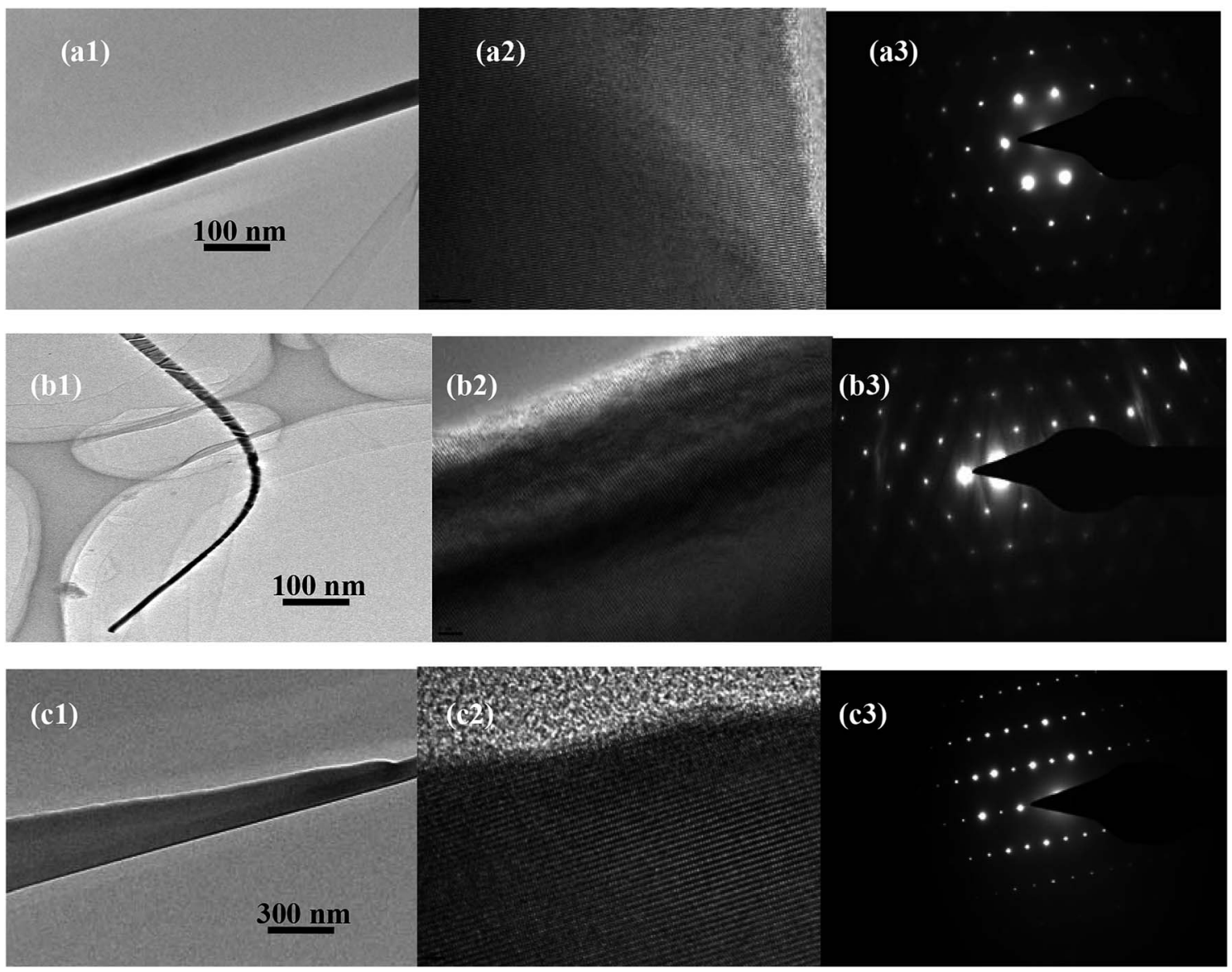

Fig. 4 TEM, high resolution TEM and selected area electron diffraction diagrams of different AZO nanostructures: (a) nanowires, (b) nanobelts, and (c) nanoplane-cone, respectively.

around $84 \mathrm{~nm}$ (for nanowires), $312 \mathrm{~nm}$ (for nanobelts), $20 \mathrm{~nm}$ and $600 \mathrm{~nm}$ (for narrow (tip) and wide (thick) parts of nanoplane-cone), respectively. The SAED pattern in Fig. 4 (M3) shows that the AZO nanostructures are single crystalline in nature and grow along the [0001] direction. The XRD and FESEM results are in agreement with the TEM analysis.

In order to study the chemical state of $\mathrm{Zn}, \mathrm{Al}$ and $\mathrm{O}$, we measured the XPS spectrum of the sample, as is shown in Fig. 5. The binding energies obtained in the XPS analysis were standardized by using $\mathrm{C} 1 \mathrm{~s}$ at $284.6 \mathrm{eV}$ as the reference. Fig. 5(a) shows the XPS survey spectrum of the AZO nanowires. No peaks of other elements except $\mathrm{Zn}, \mathrm{O}$ and $\mathrm{Al}$ are observed in the spectrum. Fig. 5(b) and (c) shows the XPS spectra of the $\mathrm{O} 1 \mathrm{~s}$ and $\mathrm{Zn} 2 \mathrm{p}_{3 / 2}$ regions for the surface of the AZO nanowires. The O $1 \mathrm{~s}$ core-level peak at $532.4 \mathrm{eV}$ indicates the -2 valence of the $\mathrm{O}$ element in the products. The peaks located at 1022.1 and $1045.2 \mathrm{eV}$ correspond to $\mathrm{Zn} 2 \mathrm{p}_{3 / 2}$ and $\mathrm{Zn} 2 \mathrm{p}_{1 / 2}$, respectively (see Fig. 5(c)). From the Fig. 5(d), the core-level spectrum of $\mathrm{Al} 2 \mathrm{p}$ peak located at $74.8 \mathrm{eV}$ is attributed to $\mathrm{Al}(\mathrm{III})$. It indicates that $\mathrm{Al}$ exists in the nanowires in the form of $\mathrm{Al}(\mathrm{III})$, but not elementary Al. On the other hand, we found that the $\mathrm{Al} 2 \mathrm{p}$ peaks located at the surface and internal lattice behave a little difference, which may be associated with the different content of oxygen.
Fig. 6 shows the PL spectra of AZO nanostructures in room temperature. The insets of Fig. 6 show the fittings of the PL spectra of crystalline AZO nanostructures in the excitonic emission region. The PL spectra of AZO nanostructures with nanowires, nanobelts and nanoplane-cone are came from a NBE emission in the ultraviolet (UV) region, and two peaks in visible light due to deep-level emission (DLE). Compared with the pure $\mathrm{ZnO}$ of $3.37 \mathrm{eV},{ }^{25,26}$ the NBE peak shifts to shorter wavelengths (blue shift) with the doping of $\mathrm{Al}$ which can be related to Moss Burstein effect. ${ }^{27,28}$ In addition, $\mathrm{Zn}^{2+}$ ions at their lattice sites by the substitution of $\mathrm{Al}^{3+}$ ions in AZO nanostructures leads to increase of the Fermi level and the broadening of optical band gap. The calculated energy gap values from Tauc formula in pervious section confirm NBE peak blue shift. Similar results are reported by other researchers. ${ }^{21}$ The AZO nanobelts have a relative stronger UV emission and the AZO nanowires have a relative stronger visible emission (see Fig. 6(d)). The reason is that the band-side excitation of the AZO semiconductor with different morphologies generally occurs near the surface of the AZO nanostructures, resulting in an uneven distribution of the excited carriers. As a result of radiative or non-radiative transitions, excess unbalanced carriers diffuse from the surface to the interior and recombine at the same time to achieve a balanced and uniform distribution. Therefore, the vast majority of 

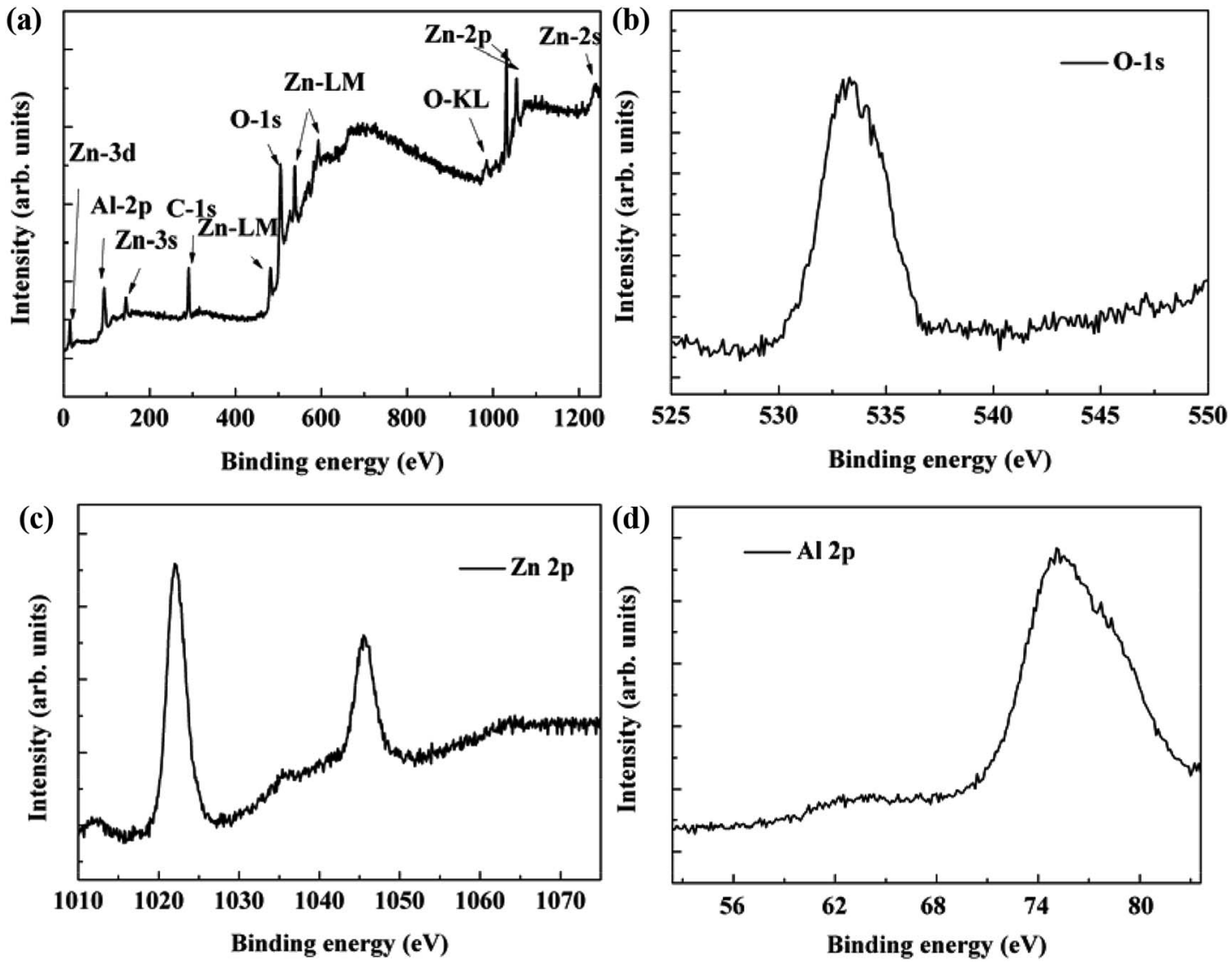

Fig. 5 (a) XPS spectra corresponding to the AZO nanowires, (b) O-1s, (c) Zn-2p, and (d) Al-2p core level of AZO nanowires.

excitations in the crystal are confined to the depth of penetration of photons below the surface. After excited by laser, for the AZO nanobelts with larger aspect ratio, most of the nonequilibrium carriers take the radiative recombination, so the ultraviolet radiation is stronger. For the AZO nanoplane-cones with smaller aspect ratio, the unbalanced carriers diffuse from surface to interior, resulting in the trap of a considerable number of electrons and holes and the reduction of the radiation recombination number of effective electrons and holes, so the ultraviolet radiation is weaker and the deep-level radiation stronger. In Fig. 3, the $\mathrm{Al}$ at\% of the AZO nanobelts is less than other samples. This means that the enhancement of visible light emission of AZO nanowires and nanoplane-cones is due to the enhancement of F-M effect with the increase of Al doping. So the UV radiation is weaker and the deep-level radiation is stronger than AZO nanobelts. Therefore, UV and visible radiation intensity changes significantly with the components, size and morphology of the material.

In addition, for different excitation laser power, the change of emission band intensity AZO nanowire and nanoplane-cone is uniform, which indicates that the overall growth morphology of AZO nanowire and nanoplane-cone is uniform. The peak ratio of UV and visible emission for three samples: nanowire $>$ nanobelts $>$ nanoplane-cone (see Fig. 6(d)), which shows that the crystallization quality of the nanowire is better than the nanobelts and nanoplane-cone. Noted that intensity of the UV emission peak increases sublinearly with excitation power as shown in the Fig. 6(d) for $325 \mathrm{~nm}$ excitations, and no appreciable shift in peak positions is observed. The experimental data can be fitted by the simple power law $I \propto W^{\mu}$, where $I$ is the PL intensity, $W$ is the excitation laser power. The dimensionless exponent $(\mu)$ represents the radiative recombination mechanism. The $\mu$ value satisfies with the relation of $1<$ $\mu<2$ for the free- and bound-exciton emission. ${ }^{29,30}$ For AZO nanostructures, $\mu$ value is 1.16 (for nanowires), 1.08 (for nanobelts) and 1.12 (for nanoplane-cone), respectively. Thus, the obtained value of $\mu(1<\mu<2)$ confirms our assignment of the observed emission band in AZO spectra to the free- and boundexciton emission.

Fig. 7(a-c) shows the LTPL spectra (UV region emission) of AZO nanostructures in the temperature range of $10-273 \mathrm{~K}$. The inset shows the Vis region emission spectra. The results show that three components with center wavelengths at 3.37, 3.36, and $3.32 \mathrm{eV}$. The peak at $3.37 \mathrm{eV}$ is caused by free excitons $(\mathrm{FX}=$ NBE) recombination. The peaks at 3.36 and $3.32 \mathrm{eV}$ can be attributed to bound excitons. The similar phenomenon obtained by H. P. He et al. ${ }^{17}$ As shown in Fig. $7(\mathrm{a}-\mathrm{c})$, the intensity of emission peak in the UV region decreased drastically with increasing temperature. Fig. 7(e) plots the intensity of the UV emission peak as a function of reciprocal temperature. The presence of two activation energy for thermal quenching is indicative of two competitive nonradiative recombination 

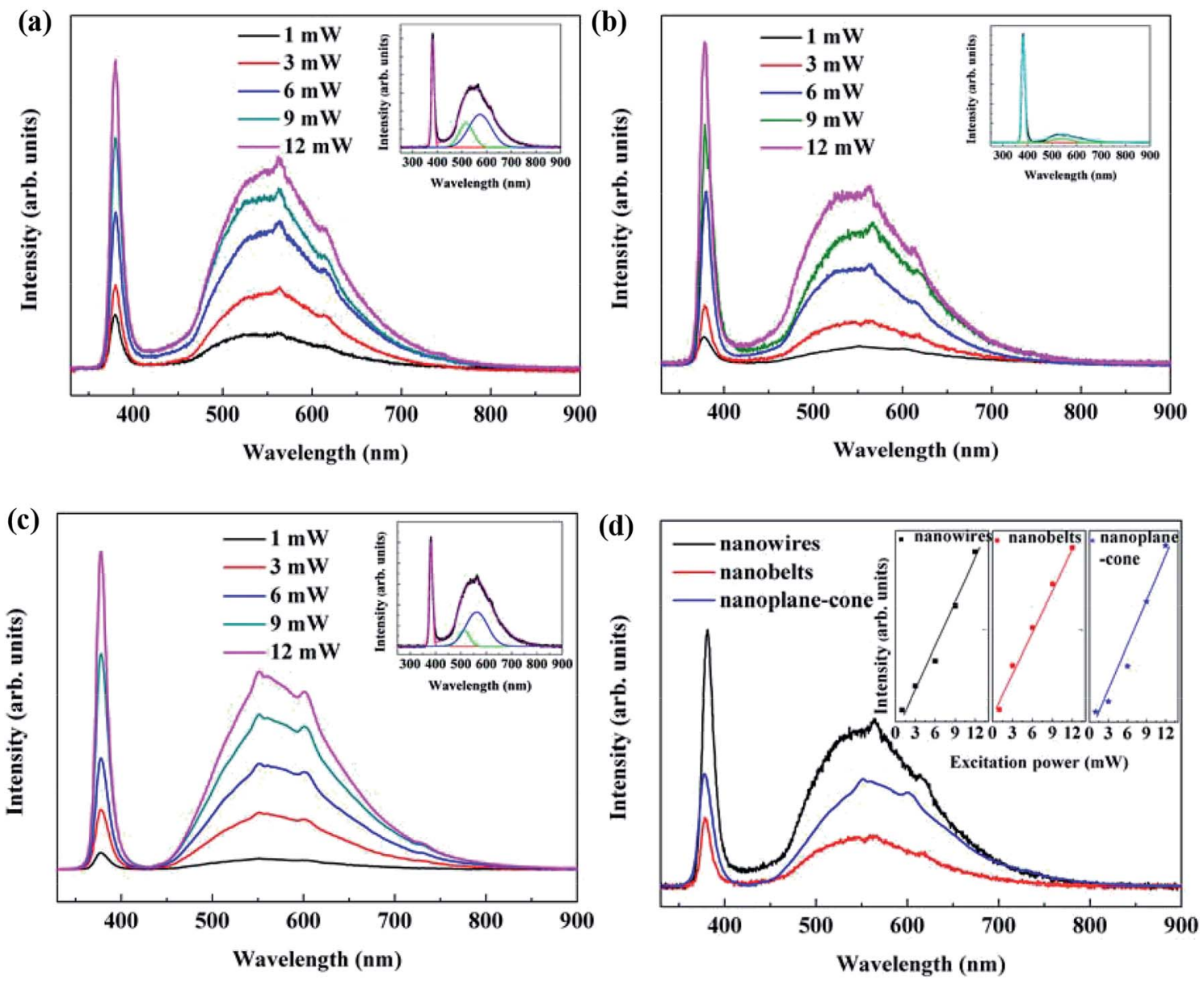

Fig. 6 RTPL spectra of AZO nanostructures with different morphologies: (a) nanowires, (b) nanobelts, and (c) nanoplane-cone, respectively. (d) The relationship between the intensity of UV emission peak and excitation power.

channels. Because our sample was doped with $\mathrm{Al}$, it is reasonable to assign the UV emission peak to excitons bound to neutral Al donors. Thus, the activation energy may represent the thermal ionization energy of the Al donors. Fig. 7(f) shows the peak positions of the FX, a line and its first longitudinal optical (LO) replica as a function of temperature. When temperature exceeds $90 \mathrm{~K}$, the dominant emission becomes the A line. As temperature further increases, the first LO-phonon replica gradually merges into the A line, resulting in the marked broadening of the NBE emission. The relative intensity of the DL emission peaks at about $\sim 2.20 \mathrm{eV}$ is strongly reduced. The wavelength locations do not shift. No obvious change was observed for peak position of visible emission in the RTPL spectra.

Illustration of the ZnO band, UV and DL emission is shown in Fig. 8. The Vis emission peak was observed in RTPL spectra of the AZO nanostructures. As shown in Fig. 8(I-VI), all emission peaks of the AZO nanostructures can be analyzed by considering the energy band diagram schematically. According to some reports, this visible wavelength emission is excited by the recombination of photogenerated hole with the singly ionized oxygen vacancy site. ${ }^{31-34}$ The UV emission is derived from the radiated composite luminescence of the forbidden band free excitons, and the blue light emission comes from the fact of the electron transition from $\mathrm{Zn}_{\mathrm{i}}$ to zinc vacancy $\left(\mathrm{V}_{\mathrm{Zn}}\right)$ or the top of the VB. For LTPL spectra, when the excitation laser light at $325 \mathrm{~nm}$ was launched in the AZO nanostructures, the electrons are excited from the VB to the $\mathrm{CB}$. Hence, the electron density is increased in the FL of Al doping. These electrons are excited and transferred to the bottom of the $\mathrm{CB}$, and recombined with holes in the VB of AZO nanostructures with radiative emission.

Fig. 9(a) shows the FE current density versus applied field (J$E)$ of AZO nanostructures with different morphologies. The current density is analyzed as a function of applied field for both samples using Fowler-Nordheim (F-N) theory. ${ }^{35,36}$ From the $J-E$ curve, the value of the EF, required to draw an EC density of $\sim 10 \mu \mathrm{A} \mathrm{cm}{ }^{-2}$, is observed to be $\sim 1 \mathrm{~V} \mu \mathrm{m}^{-1}$. At a current density of $0.1 \mu \mathrm{A}$, the turn-on $\mathrm{EF}$ of AZO nanostructures under UV illumination are $4.42 \mathrm{~V} \mathrm{\mu m}^{-1}$ (for nanowires), $5.28 \mathrm{~V} \mathrm{\mu m}^{-1}$ (for nanobelts) and $2.52 \mathrm{~V} \mathrm{\mu m}^{-1}$ (for nanoplane-cone), respectively. To understand the mechanism of the enhanced FE behavior of the AZO nanostructures, the energy band diagrams of AZO nanostructures schematically depicted in Fig. 9(b). Under UV illumination, the electrons transferred from the $\mathrm{CB}$ to Fermi energy level. The work function of AZO $(4.75 \mathrm{eV})$ is smaller than $\mathrm{ZnO}(5.3 \mathrm{eV}) .^{37}$ The decreased work function 

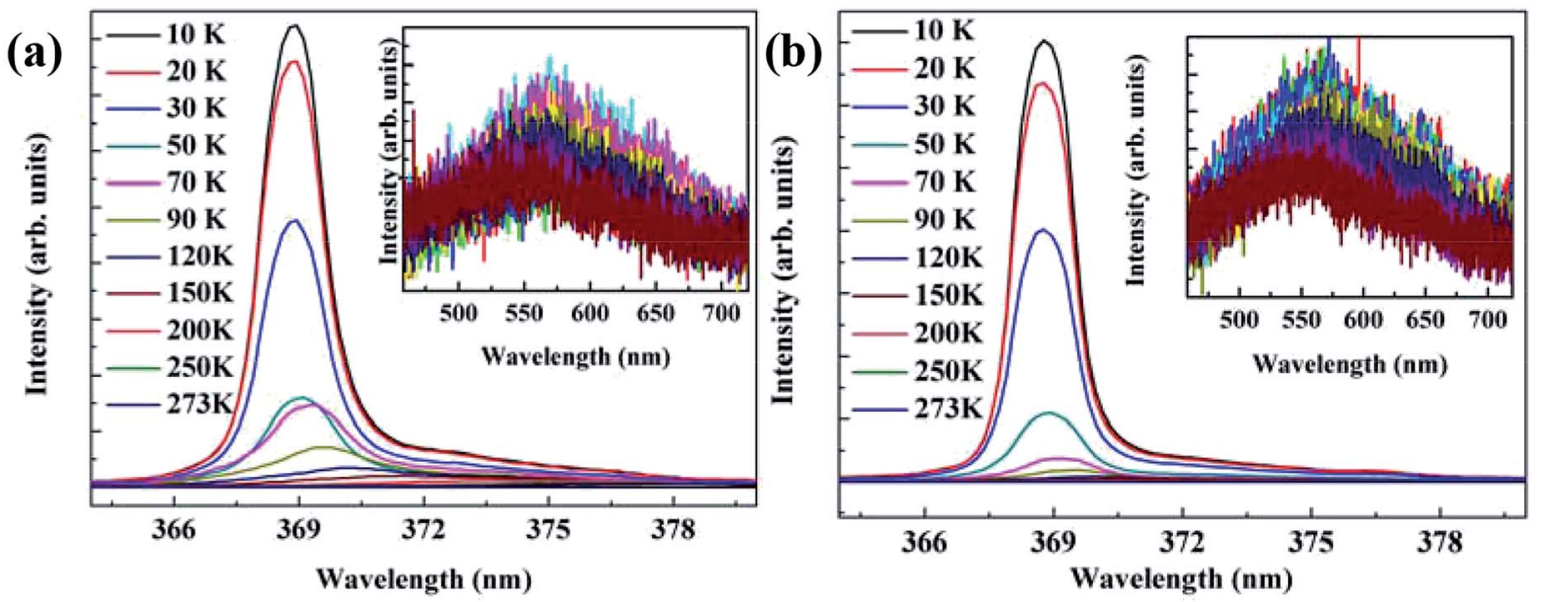

(c)

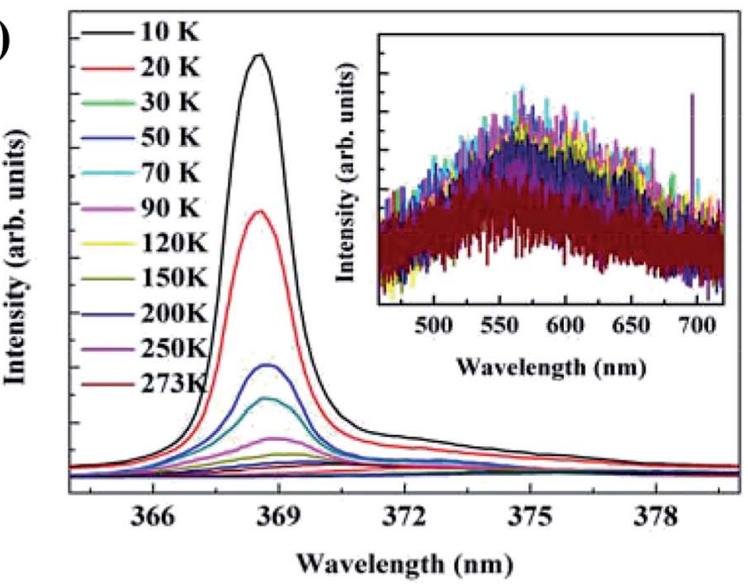

(d)
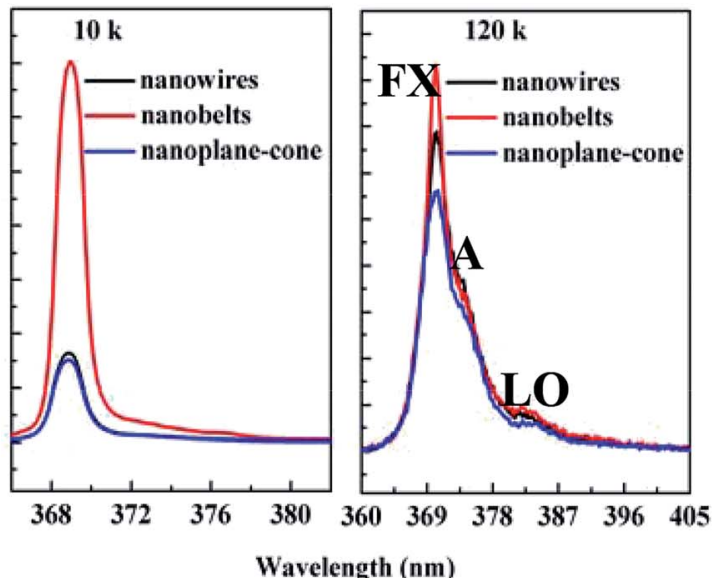
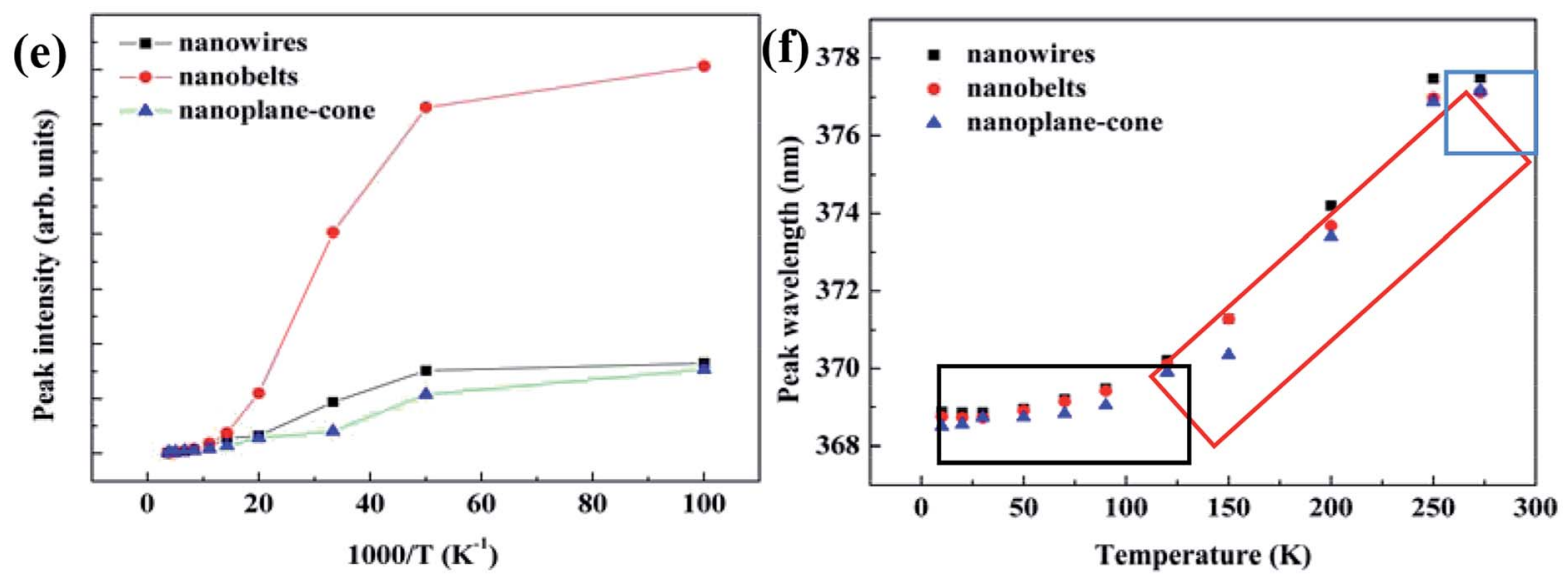

Fig. 7 LTPL spectra of AZO nanostructures with different morphologies: (a) nanowires, (b) nanobelts, and (c) nanoplane-cone, respectively. (d) LTPL spectra of AZO nanostructures with different morphologies at $10 \mathrm{~K}$ and $120 \mathrm{~K}$. (e) The intensity of the UV emission peak as a function of reciprocal temperature. (f) The peak positions of the FX as a function of temperature.

lowered the turn-on EF. Similar nonlinear $J-E$ plots have been reported for $\mathrm{ZnO}$ and doped or decorated $\mathrm{ZnO}$ semiconductors, such as Y. G. Fang et $a .^{34}$ found that the turn-on EF of ZnO nanowires arrays at different reaction decreases from 4.56 to $3.69 \mathrm{~V} \mathrm{\mu m}^{-1}$. S. S. Warule et al. found the turn-on field of $\mathrm{ZnO}$ nanopencils is $2.15 \mathrm{~V} \mu \mathrm{m}^{-1}{ }^{35} \mathrm{C}$. L. Hsu et $a l .{ }^{36}$ found that the FE turn-on $\mathrm{EF}$ of $\mathrm{Al}$ doped $\mathrm{ZnO}$ nanowires are from 2.8 to $1.3 \mathrm{~V}$ $\mu \mathrm{m}^{-1}$. Compare with the present a part of results, the pure and Al doped ZnO nanostructures exhibit a higher applied field value; the reason comes from that the randomly distribution of nanowire arrays better displays the FE performance. In this work, our results showed that the enhanced FE performance of the AZO nanoplane-cone can be attributed to point effect compared to that of other AZO nanostructures. For $\mathrm{ZnO}$ 


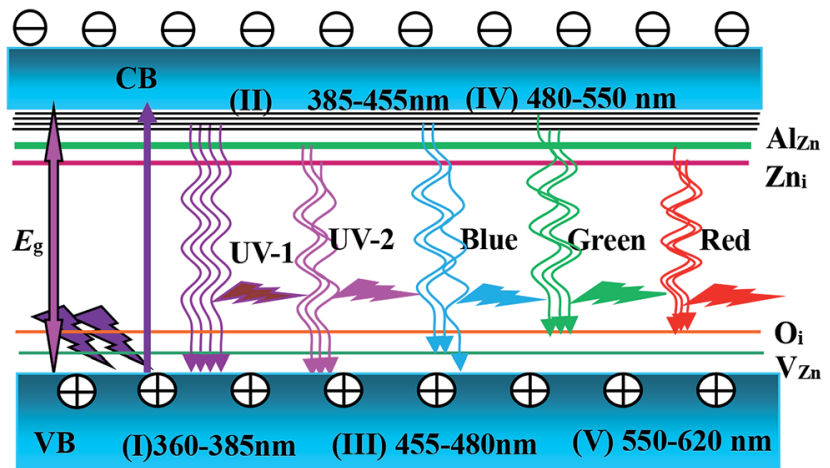

Fig. 8 Energy band diagram of the AZO system.

nanoplane-cone, its excellent FE property can also attribute to the special morphology. The small tip size and high aspect ratio of nanoplane-cone morphology can generate a high local electric field, which will decrease the FE potential barrier and increase the FE current. The experimental results demonstrate that the FE properties of AZO nanostructures depend on their morphology, structure and crystallinity. The similar phenomenon in $\mathrm{ZnO}$ nanograsses has been reported by H. M. Dong et al. $^{37}$

The nonlinear absorption characteristics of AZO nanowires, nanobelts, and nanoplane-cone were studied by Z-scan method with the wavelength at $800 \mathrm{~nm}$ and pulse width at $150 \mathrm{fs}$. Under the laser excitation intensity at $500 \mathrm{~nJ}$, Fig. 10(a) shows the open-aperture Z-scan transmittance curves of AZO nanostructures with the nanowires, nanobelts, and nanoplane-cone morphologies. It can be seen form Fig. 10(a), the openaperture Z-scan transmittance curves of AZO nanowires, nanobelts, and nanoplane-cone are valley. And the nonlinear absorption mechanism of AZO nanostructures is reverse saturable absorption (RSA). The laser excitation wavelength falls in the wing region of the exciton absorption, satisfying the condition for the occurrence of a three photon absorption (3PA) process $\left(E_{\mathrm{g}} / 3<h \nu<E_{\mathrm{g}} / 2\right.$, see inset Fig. 10(a)). The similar analysis process has been reported ${ }^{38-43}$ From the experimental results, the 2PA induced conduction band or defect state RSA (two-step 3PA) behavior of AZO nanostructures with different morphologies has been determined. With standard $\mathrm{Z}$ scan theory, we extract the effective nonlinear absorption coefficients with the sample approximation. The nonlinear absorption coefficient $\left(\alpha_{3}\right)$ was calculated using $T_{3 \mathrm{PA}}=1 /\left[1+2 \alpha_{3} L_{\text {eff }}\left(I_{0} /(1+\right.\right.$ $\left.\left.\left.\left(z / z_{0}\right)^{2}\right)\right)^{2}\right]^{1 / 2} .38,39$ Where $I_{0}=c /\left(\pi r^{2}\right), c=A / B ; L_{\text {eff }}=(1-$ $\left.\exp \left(-2 \alpha_{0} L\right)\right) / 2 \alpha_{0}, \alpha_{0}=-(1 / L) \ln T_{\mathrm{L}} . I_{0}$ is the laser intensity at the focus; $A$ is the laser energy; $B$ is the pulse width; $c$ is the peak power; $r$ is the focal spot radius; $L_{\text {eff }}$ is the effective thickness of the sample; $L$ is the actual thickness of the sample; $T_{\mathrm{L}}$ is the linear transmittance of the sample. A fit to above the equation to the open aperture data Z-scan indicates that $\alpha_{3}$ is $6.48 \times 10^{-2}$ $\mathrm{cm}^{3} \mathrm{GW}^{-2}, 8.72 \times 10^{-2} \mathrm{~cm}^{3} \mathrm{GW}^{-2}$ and $2.42 \times 10^{-2} \mathrm{~cm}^{3} \mathrm{GW}^{-2}$ for nanowires, nanobelts, and nanoplane-cone, respectively. The nonlinear absorption coefficient for three AZO nanostructures: nanobelts $>$ nanowire $>$ nanoplane-cone. For AZO nanobelts, the maximum nonlinear absorption coefficient is $8.72 \times 10^{-2} \mathrm{~cm}^{3} \mathrm{GW}^{-2}$. This is because the incorporation of excess $\mathrm{Al}$ into $\mathrm{ZnO}$ completely changes the original morphology of the material, and the nonlinear absorption properties of the AZO nanostructures are suppressed. In addition, M. G. Vivas et al. ${ }^{41}$ reported the reverse saturable, two- and three-photon absorption properties of $\mathrm{ZnO}$ at $500 \mathrm{~nm}, 730 \mathrm{~nm}$ and $820 \mathrm{~nm}$, respectively. In contrast, the 3PA coefficient of the AZO nanostructures is larger than that of $\mathrm{ZnO}$ in the reference. Because of the $\mathrm{Al}$ donor doped $\mathrm{ZnO}$ provides more electrons, which lead to value of CB absorption cross-section of AZO nanostructures was increased, thereby the nonlinear absorption was increased. To interpret this intensity dependent nonlinear absorption coefficient, we present a possible optical physical process under $800 \mathrm{~nm}$ laser pulse excitation, as shown in Fig. 10(b). The system simultaneously absorbs two identical photons, promoting an electron from ground state to excited state by virtual states. Subsequently, the electron is excited to higherlying excited state by absorbing another single photon, resulting in 2PA-induced RSA. The similar analysis process has been

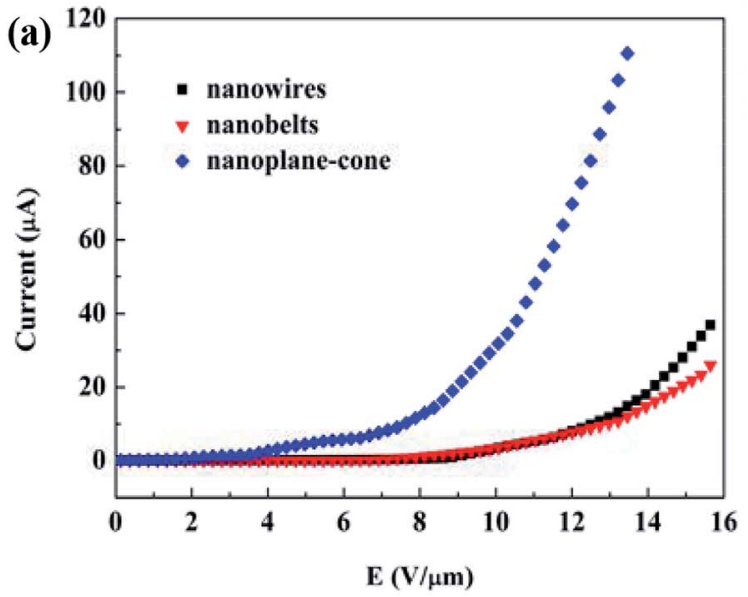

(b)

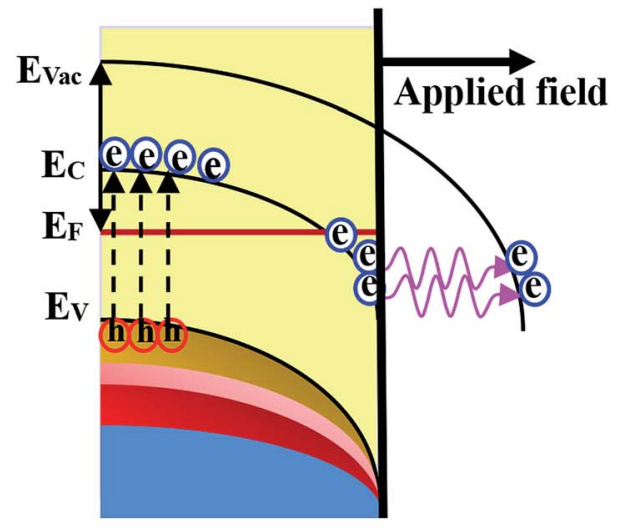

Fig. 9 (a) Emission current-voltage characteristics of the AZO nanostructures. (b) Band diagrams of AZO nanostructures under UV light. 


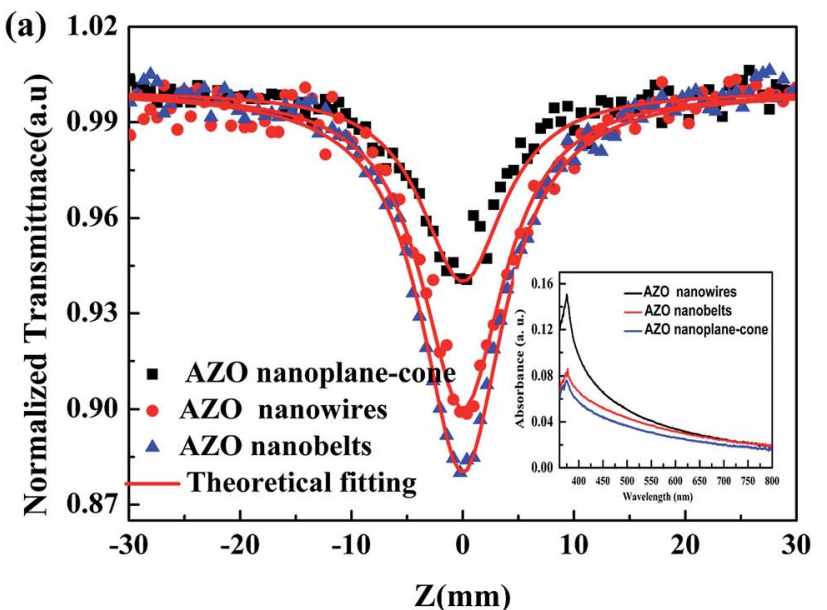

(b)

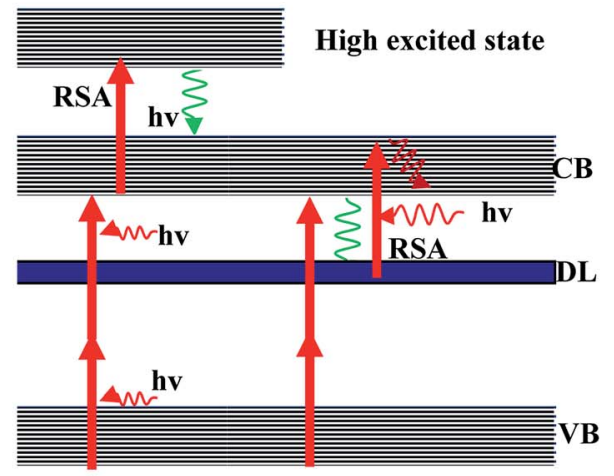

(I)

(II)

Fig. 10 (a) Transmittance curves of AZO nanostructures measured at $800 \mathrm{~nm}$ wavelength with 100 fs pulse width. (b) The nonlinear absorption mechanism diagram of AZO nanostructures.

reported.44-49 Here, the Fig. 10(b) presents the nonlinear absorption mechanism diagram of AZO nanostructures upon direct excitation with $800 \mathrm{~nm}$. In Fig. 10b(I) and (II), the AZO nanostructures have 2PA induced conduction band and 2PA induced defect state RSA at $800 \mathrm{~nm}$ in the femtosecond domain. Due to the incorporation of $\mathrm{Al}$, the position of $\mathrm{Zn}$ is replaced, the impurity level $V_{\mathrm{O}}$ and $\mathrm{Zn}_{\mathrm{i}}$ are increased. And a small amount of $\mathrm{Al}$ is incorporated (see Fig. 3), the impurity defect state increases, and the nonlinear absorption of AZO nanostructures is the 2PA induced conduction band or defect state RSA behavior.

\section{Conclusions}

In summary, we investigated the structure, PL and FE properties of 1D-AZO nanostructures with three morphologies by a CVD method. The mechanism of the growth, PL and FE properties for AZO nanostructures is analyzed. The enhanced FE properties were achieved by tailoring the morphological design of AZO nanostructures. The FE studies reveal the turn-on EF of AZO nanostructures under UV illumination are $4.42 \mathrm{~V} \mathrm{\mu m}^{-1}$ (for nanowires), $5.28 \mathrm{~V} \mathrm{\mu m}^{-1}$ (for nanobelts) and $2.52 \mathrm{~V} \mathrm{\mu m}^{-1}$ (for nanoplane-cone), respectively. The FE measurements indicated that the nanoplane-cone has a relative smaller turn-on EF than other kinds of samples. The femtosecond open-aperture Z-scan results show that the nonlinear absorption property of AZO nanostructures is RSA properties. And the nonlinear absorption mechanism of AZO nanostructures is 3PA induced RSA. It is calculated that the order of magnitude of the nonlinear absorption coefficient for the all AZO nanostructures is $\sim 10^{-2}$ $\mathrm{cm}^{3} \mathrm{GW}^{-2}$. Our results indicate that AZO nanostructures show great potential as flat panel displays, high brightness electron sources, photoanodes in FE devices and nonlinear optical devices.

\section{Conflicts of interest}

There are no conflicts to declare.

\section{Acknowledgements}

This work was supported by the National Natural Science Foundation of China (11504072). University Nursing Program for Young Scholars with Creative Talents in Heilongjiang Province (No. UNPYSCT-2016179).

\section{References}

1 A. B. Djurišić, X. Chen, Y. H. Leung and A. M. C. Ng, ZnO nanostructures: growth, properties and applications, $J$. Mater. Chem., 2012, 22, 6526-6535.

2 S. Singh, P. Thiyagarajan, K. M. Kant, D. Anita, S. Thirupathiah, N. Rama, B. Tiwari, M. Kottaisamy and M. S. R. Rao, Structure, microstructure and physical properties of ZnO based materials in various forms: bulk, thin film and nano, J. Phys. D: Appl. Phys., 2007, 40, 63126327.

3 C. Klingshirn, J. Fallert, H. Zhou, J. Sartor, C. Thiele, F. Maier-Flaig, D. Scherder and H. Kalt, 65 years of ZnO research - old and very recent results, Phys. Status Solidi B, 2010, 247, 1424-1447.

4 C. L. Hsu and S. J. Chang, Doped ZnO 1D nanostructures: synthesis, properties, and photodetector application, Small, 2014, 10, 4562-4585.

5 S. Suwanboon, P. Amornpitoksuk and A. Sukolrat, Dependence of optical properties on doping metal, crystallite size and defect concentration of M-doped $\mathrm{ZnO}$ nanopowders ( $\mathrm{M}=\mathrm{Al}, \mathrm{Mg}$, Ti), Ceram. Int., 2011, 37, 13591365.

6 Y. Zhao, R. J. Tong, M. Q. Chen and F. Xia, Relative humidity sensor based on hollow core fiber filled with GQDs-PVA, Sens. Actuators, B, 2019, 284, 96-102.

7 R. Deng, B. Yao, Y. F. Li, T. Yang, B. H. Li, Z. Z. Zhang, C. X. Shan, J. Y. Zhang and D. Z. Shen, Influence of oxygen/argon ratio on structural, electrical and optical properties of Ag-doped ZnO thin films, J. Cryst. Growth, 2010, 312, 1813-1816. 
8 J. T. Yang, R. Fan, J. Li and F. L. Meng, Hydrogen leakage detectors based on a polymer microfiber decorated with $\mathrm{Pd}$ nanoparticles, IEEE Sens. J., 2019, 19(16), 6736-6741.

9 S. J. Young, C. C. Yang and L. T. Lai, Review-growth of Al-, $\mathrm{Ga}-$, and In-doped $\mathrm{ZnO}$ nanostructures via a lowtemperature process and their application to field emission devices and ultraviolet photosensors, J. Electrochem. Soc., 2017, 164, B3013-B3028.

10 B. Paul, B. Singh, S. Ghosh and A. Roy, A comparative study on electrical and optical properties of group III (Al, Ga, In) doped ZnO, Thin Solid Films, 2016, 603, 21-28.

11 P. P. Sahay and R. K. Nath, Al-doped ZnO thin films as methanol sensors, Sens. Actuators, B, 2008, 134, 654-659.

12 F. Khan, S. Ameen, M. Song and H. S. Shin, Influence of excitation wavelength on photoluminescence spectra of $\mathrm{Al}$ doped ZnO films, J. Lumin., 2013, 134, 160-164.

13 M. Chen, Z. L. Pei, C. Sun, L. S. Wen and X. Wang, Surface characterization of transparent conductive oxide Al-doped ZnO films, J. Cryst. Growth, 2000, 220, 254-262.

14 M. Shirazi, R. S. Dariani and M. R. Toroghinejad, Influence of doping behavior of $\mathrm{Al}$ on nanostructure, morphology and optoelectronic properties of $\mathrm{Al}$ Doped $\mathrm{ZnO}$ thin film grown on FTO substrate, J. Mater. Sci.: Mater. Electron., 2016, 27, 10226-10236.

15 Y. Liu, H. Zhang, X. An, C. Gao, Z. Zhang, J. Zhou, M. Zhou and E. Xie, Effect of $\mathrm{Al}$ doping on the visible photoluminescence of $\mathrm{ZnO}$ nanofibers, J. Alloys Compd., 2010, 506, 772-776.

16 A. Mohanta, J. G. S. Simmons Jr, H. O. Everitt, G. Shen, S. M. Kim and P. Kung, Effect of pressure and Al doping on structural and optical properties of $\mathrm{ZnO}$ nanowires synthesized by chemical vapor deposition, J. Lumin., 2014, 146, 470-474.

17 H. P. He, H. P. Tang, Z. Z. Ye, L. P. Zhu, B. H. Zhao, L. Wang and X. H. Li, Temperature-dependent photoluminescence of quasialigned Al-doped ZnO nanorods, Appl. Phys. Lett., 2007, 90, 023104.

18 K. J. Chen, T. H. Fang, F. Y. Hung, L. W. Ji, S. J. Chang, S. J. Young and Y. J. Hsiao, The crystallization and physical properties of Al-doped ZnO nanoparticles, Appl. Surf. Sci., 2008, 254, 5791-5795.

19 F. Giovannelli, A. N. Ndimba, P. Diaz-Chao, M. MotelicaHeino, P. I. Raynal, C. Autret and F. Delorme, Synthesis of Al doped $\mathrm{ZnO}$ nanoparticles by aqueous coprecipitation, Powder Technol., 2014, 262, 203-208.

20 K. H. Kim, T. Umakoshi, Y. Abe, M. Kawamura and T. Kiba, Morphological properties of Al-doped $\mathrm{ZnO}$ nano/ microstructures, Superlattices Microstruct., 2016, 91, 188192.

21 J. L. Wang, T. Y. Hsieh, P. Y. Yang, C. C. Hwang, D. C. Shye and I. C. Lee, Oxygen annealing effect on field-emission characteristics of hydrothermally synthesized Al-doped ZnO nanowires, Surf. Coat. Technol., 2013, 231, 423-427.

22 F. Maldonado and A. Stashans, Al-doped ZnO: Electronic, electrical and structural properties, J. Phys. Chem. Solids, 2010, 71, 784-787.
23 Z. X. Lin, Y. A. Zhang, Y. Ye, X. T. Zhou and T. L. Guo, Synthesis and photoelectric properties of $\mathrm{ZnO}$ nanostructure with different morphologies via hydrothermal method, Mater. Technol., 2012, 27, 350-354.

24 X. Y. Yan, K. X. Zhang, C. B. Yao and Q. H. Li, Ultrafast nonlinear optical properties and optical Kerr effect of Indoped ZnO nanowires, Mater. Lett., 2016, 176, 49-51.

25 Y. V. Kaneti, Z. Zhang, J. Yue, Q. M. D. Zakaria, C. Chen, X. Jiang and A. Yua, Crystal plane-dependent gas-sensing properties of zinc oxide nanostructures: experimental and theoretical studies, Phys. Chem. Chem. Phys., 2014, 16, 11471-11480.

26 A. K. Radzimska and T. Jesionowski, Zinc Oxide-from synthesis to application: A review, Materials, 2014, 7, 28332881.

27 X. J. Wang, I. A. Buyanova, W. M. Chen, C. J. Pan and C. W. Tu, Effects of stoichiometry on defect formation In ZnO epilayers grown by molecular-beam epitaxy: an optically detected magnetic resonance study, J. Appl. Phys., 2008, 103, 023712.

28 Y. C. Kong, D. P. Yu, B. Zhang, W. Fang and S. Q. Feng, Ultraviolet-emitting ZnO nanowires synthesized by a physical vapor deposition approach, Appl. Phys. Lett., 2001, 78, 407.

29 T. Schmidt, K. Lischka and W. Zulehner, Excitation-power dependence of the near-band-edge photoluminescence of semiconductors, Phys. Rev. B: Condens. Matter Mater. Phys., 1992, 45, 8989-8994.

30 H. Yan, Y. Yang, Z. Fu, B. Yang, J. Zuo and S. Fu, Excitationpower dependence of the near-band-edge photoluminescence of ZnO inverse opals and nanocrystal films, J. Lumin., 2008, 128, 245-249.

31 K. Saravanan, B. K. Panigrahi, R. Krishnan and K. G. M. Nair, Surface plasmon enhanced photoluminescence and Raman scattering of ultra-thin $\mathrm{ZnO}-\mathrm{Au}$ hybrid nanoparticles, J. Appl. Phys., 2013, 113, 033512.

32 H. P. He, Q. Yang, C. Liu, L. W. Sun and Z. Z. Ye, SizeDependent Surface Effects on the Photoluminescence in ZnO Nanorods, J. Phys. Chem. C, 2011, 115, 58-64.

33 V. A. Fonoberov, K. A. Alim, A. A. Balandin, F. Xiu and J. Liu, Photoluminescence investigation of the carrier recombination processes in $\mathrm{ZnO}$ quantum dots and nanocrystals, Phys. Rev. B: Condens. Matter Mater. Phys., 2006, 73, 165317.

34 Y. G. Fang, K. M. Wong and Y. Lei, Synthesis and field emission properties of different $\mathrm{ZnO}$ nanostructure arrays, Nanoscale Res. Lett., 2012, 7, 197.

35 S. S. Warule, N. S. Chaudhari, R. T. Khare, J. D. Ambekar, B. B. Kale and M. A. More, Single step hydrothermal approach for devising hierarchical $\mathrm{Ag}-\mathrm{ZnO}$ heterostructures with significant enhancement in field emission performance, CrystEngComm, 2013, 15, 7475-7483.

36 C. L. Hsu, C. W. Su and T. J. Hsueh, Enhanced field emission of Al-doped $\mathrm{ZnO}$ nanowires grown on a flexible polyimide substrate with UV exposure, RSC Adv., 2014, 4, 2980-2983. 
37 H. M. Dong, Y. H. Yang and G. W. Yang, Growth and field emission property of ZnO nanograsses, Mater. Lett., 2014, 115, 176-179.

38 Y. D. Zhang, Z. Y. Zhao, C. B. Yao, L. Yang, J. Li and P. Yuan, The nonlinear absorption and optical limiting in phenoxyphthalocyanines Liquid in nano-and femto-second regime: Experimental studies, Opt. Laser Technol., 2014, 58(6), 207214.

39 X. Y. Yan, C. B. Yao, J. Li, J. Y. Hu, Q. H. Li and S. B. Yang, Structural, photoluminescence and picosecond nonlinear optical effect of In-doped $\mathrm{ZnO}$ nanowires, Opt. Mater., 2016, 55, 73-77.

40 J. He, Y. Qu, H. Li, J. Mi and W. Ji, Three-photon absorption in ZnO and ZnS crystals, Opt. Express, 2005, 13, 9235-9247.

41 M. G. Vivas, T. Shih, T. Voss, E. Mazur and C. R. Mendonca, Nonlinear spectra of ZnO: reverse saturable, two- and threephoton absorption, Opt. Express, 2010, 18(9), 9628-9633.

42 U. P. Shaik, P. A. Kumar, M. G. Krishna and S. V. Rao, Morphological manipulation of the nonlinear optical response of $\mathrm{ZnO}$ thin films grown by thermal evaporation, Mater. Res. Express, 2014, 1, 046201.

43 B. Gu, W. Ji, P. S. Patil, S. M. Dharmaprakash and H. T. Wang, Two-photon-induced excited-state absorption: Theory and experiment, Appl. Phys. Lett., 2008, 92, 091118.
44 B. Gu, Y. Sun and W. Ji, Two-photon-induced excited-state nonlinearities, Opt. Express, 2008, 16, 17745-17751.

45 B. Gu, K. Lou, H. T. Wang and W. Ji, Dynamics of twophoton-induced three-photon absorption in nanosecond, picosecond, and femtosecond regimes, Opt. Lett., 2010, 35, 417-419.

46 R. L. Sutherland, M. C. Brant, J. Heinrichs, J. E. Slagle, D. G. McLean and P. A. Fleitz, Excited state characterization and effective three-photon absorption model of two-photon-induced excited-state absorption in organic push-pull charge-transfer chromophores, J. Opt. Soc. Am. B, 2005, 22, 1939-1948.

47 P. A. Kurian, C. Vijayan, C. S. S. Sandeep, R. Philip and K. Sathiyamoorthy, Two-photon-assisted excited state absorption in nanocomposite films of $\mathrm{PbS}$ stabilized in a synthetic glue matrix, Nanotechnology, 2007, 18, 075708.

48 T. C. Sabari Girisun, M. Saravanana and V. Rao Soma, Wavelength-dependent nonlinear optical absorption and broadband optical limiting in $\mathrm{Au}-\mathrm{Fe}_{2} \mathrm{O}_{3}-\mathrm{rGO}$ nanocomposites, ACS Appl. Nano Mater., 2018, 111, 63376348.

49 F. Wu, G. L. Zhang, W. Tian, W. J. Chen, G. F. Zhao, S. D. Cao and W. Xie, Two-photon absorption and two-photon assisted excited-state absorption in $\mathrm{CdSe}_{0.3} \mathrm{~S}_{0.7}$ quantum dots, J. Opt. A: Pure Appl. Opt., 2009, 11, 065206. 